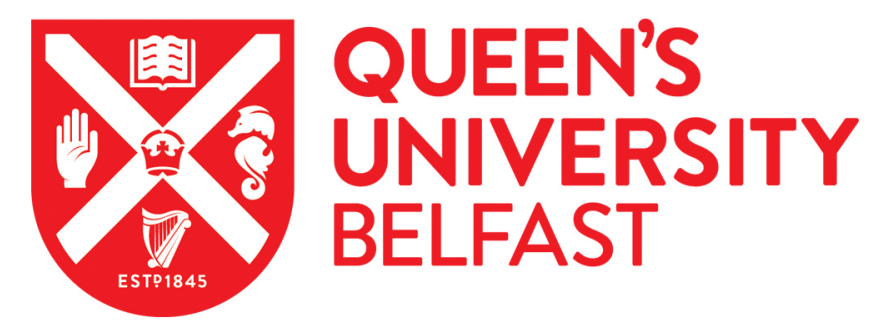

\title{
Laboratory investigations into the cause of multiple serious and fatal food poisoning incidents in Uganda during 2019
}

Haughey, S., Chevallier, O., McVey, C., \& Elliott, C. (2021). Laboratory investigations into the cause of multiple serious and fatal food poisoning incidents in Uganda during 2019. Food Control, 121.

https://doi.org/10.1016/j.foodcont.2020.107648

\section{Published in:}

Food Control

\section{Document Version:}

Peer reviewed version

Queen's University Belfast - Research Portal:

Link to publication record in Queen's University Belfast Research Portal

\section{Publisher rights}

Copyright 2021 Elsevier.

This manuscript is distributed under a Creative Commons Attribution-NonCommercial-NoDerivs License

(https://creativecommons.org/licenses/by-nc-nd/4.0/), which permits distribution and reproduction for non-commercial purposes, provided the author and source are cited.

\section{General rights}

Copyright for the publications made accessible via the Queen's University Belfast Research Portal is retained by the author(s) and / or other copyright owners and it is a condition of accessing these publications that users recognise and abide by the legal requirements associated with these rights.

Take down policy

The Research Portal is Queen's institutional repository that provides access to Queen's research output. Every effort has been made to ensure that content in the Research Portal does not infringe any person's rights, or applicable UK laws. If you discover content in the Research Portal that you believe breaches copyright or violates any law, please contact openaccess@qub.ac.uk. 
1 Title: Laboratory investigations into the cause of multiple serious and fatal food poisoning incidents in

$2 \quad$ Uganda during 2019

3

4

5

6

\section{Authors}

Haughey, S.A*., Chevallier, O.P., McVey, C., Elliott, C.T

ASSET Technology Centre, Institute for Global Food Security, School of Biological Sciences, Queen's University Belfast, 19 Chlorine Gardens, Belfast, Northern Ireland, BT9 5DL

*Corresponding author: s.a.haughey@qub.ac.uk

\section{Highlights}

- International response to food poisoning incidents

- Array of analytical methodologies used in investigation

- Tropane alkaloids implicated as source

- All outbreaks linked to one source of contaminated food

\section{Abstract}

During 2019 a series of food poisoning events and deaths occurred in Uganda due to an unknown causative agent. In response the World Food Programme (WFP) initiated investigations into the incidents which included contacting expert laboratories to analyse the main suspect product known as Super Cereal. The laboratories used a broad gamut of their testing capabilities to determine the cause of the incidents. This included targeted and non-targeted methodologies such as LC-MS/MS, QToF-MS and spectroscopic techniques coupled to chemometrics. The conclusion of the investigation was that the cause of the food poisoning was due to the presence of the Tropane alkaloids, atropine and scopolamine, in the Super Cereal. These alkaloids were found to be present due to the incorporation of Datura seeds during production of the Super Cereal. Furthermore, the data generated showed all outbreaks were caused by a single batch of the Super Cereal.

\section{Keywords}

Food Poisoning, Tropane Alkaloids, Atropine, Scopolamine. 


\section{Introduction}

\section{Context of the Super Cereal Incident in Uganda}

This paper outlines the laboratory investigation into a number of serious food poisoning episodes which occurred in Uganda in 2019. This was in response to a World Food Programme (WFP) request to several expert laboratories to support their own investigations into the issues. In all the incidents recorded a product known as 'Super Cereal' was suspected of causing the illnesses and this paper outlines steps taken to investigate this product and identify the causative agents.

In terms of the sequence of events, between the $13^{\text {th }}$ and $20^{\text {th }}$ March 2019 a total of 278 cases of food related illness were reported in the Amudat and Napak districts of the Karamoja Region of Uganda. Five fatalities were recorded as being caused by the illness and the remaining 273 affected individuals made a full recovery. Nine new cases were reported on the $9^{\text {th }}$ April, and all that fell ill recovered. These appeared to be linked to the first episode as all had consumed the same suspect batch of Super Cereal (SC) food, which had been stored away since the March incident. In a third, and seemingly different incident, 33 cases of food poisoning were reported in the Lamwo District of Uganda, some $400 \mathrm{~km}$ from Amudat between the $28^{\text {th }}$ and $29^{\text {th }}$ August. However, again SC was suspected of causing the issues, but this material was from a completely different supply chain which was extremely worrying. While two of the cases were recorded as being severe no fatalities were recorded and all made a full recovery. No clear link between the first and third incidents could be established at that time. The potential to have to cease all supplies of Super Cereal into Africa was a real risk.

In all three incidents the symptoms recorded were very similar. A rapid onset (one to two hours) after consumption of SC, patients presented with a range of symptoms including - headache, abdominal pain, dry mouths, sticky saliva, body itching, mental confusion dizziness, paleness and dilated pupils.

A number of UN Agencies (World Health Organization, WFP) and the Ministry of Health in Uganda supported by the Center for Disease Control (CDC) in the United States were active in investigating the cause of the outbreaks(Flynn \& Beach, 2019). In this paper the actions taken by the WFP supported by scientific evidence provided by the Institute for Global Food Security, Queen's University, Belfast UK, Merieux Nutrisciences, and the Center for Food Safety and Applied Nutrition, United States Food and Drug 
Administration, USA are detailed (Croley, Knolhoff, O’ Donnell, Mangrum, Fong Sam, Callahan, \& Henderson, 2020).

\section{Actions taken by WFP following the initial reports of illness}

Between the $13^{\text {th }}$ and $15^{\text {th }}$ March WFP suspended the distribution of SC in the affected areas. On the $16^{\text {th }}$ March WFP stopped distribution of SC across the country as a precautionary measure. The Ugandan Government, Police and WFP collected samples of SC from the affected districts. There were no reports of any anomaly observed in any of the samples. On the $17^{\text {th }}$ March the WFP initiated the retrieval of SC stocks from affected areas. These were held by the UN and local police. At the same time a community engagement plan was launched to inform the local population. Samples were dispatched to a number of laboratories for analysis. Preliminary microbiological testing did not show any evidence of cause. Further test data was made available by WFP on the $26^{\text {th }}$ March and this indicated no evidence of pesticides, mycotoxins or heavy metal contamination of SC to be the cause of illness. Further testing of SC samples was undertaken independently using untargeted analysis at three laboratories. All laboratories reported that they had found the presence of several tropane alkaloids, such as atropine and scopolamine to be present at parts per million concentrations in tested samples, levels at which acute toxicity are highly likely to be exhibited. Based on the lack of any other potential causative agents being found, and the symptoms of those who became ill after consumption that had many features associated with alkaloid poisoning, this was concluded to be the most likely cause of the first two outbreaks(Whitworth, 2019). However, while no link between these incidents and the third outbreak had been established, it was recognized that the same toxic agents were the likely cause. This paper concentrates on the analysis of samples taken during the first and third incidents.

\section{Tracking the source of contaminated Super Cereal}

The supply chains for SC are complex but this is common with many food products that are processed and transported across national boundaries. Based on the lot numbers of the contaminated SC (2018EX017, 2018EX011, 2018EX025) the supplier was identified as a Turkish company. Products with the same batch number were shipped from a port in Turkey to Algeria, Tanzania and Kenya. The product in Kenya was dispatched to a number of other African countries, Uganda, Tanzania, Central African Republic, Rwanda 
and Somalia. Along these supply chains there were a series of inspections of product and no issues in terms of quality or safety were noted. In the product that reached Uganda, this was transported from a central warehouse in Karamoja and onto other warehouses in Kotido, Kaabong and Moroto where further distribution to around 90 health centres occurred. Again, during the in-country distribution no irregularities were reported.

A technical inspection of the Turkish company was performed on or around the $17^{\text {th }}$ April. Major systems failures were recorded in quality management procedures. These have been detailed in a second report on the Ugandan incidents (Abia, Nugent, Montgomery, \& Elliott, 2020). 


\section{Materials and methods}

\subsection{Sample collection}

Merieux Nutrisciences was mandated by WFP for the investigation of the 72 samples collected during the WFP sampling campaign following the $1^{\text {st }}$ incident. These 72 samples were distributed in the following manner: 10 samples from retention stock in Turkey, 15 samples drawn from households in Uganda and 47 samples from storage warehouse in Uganda, Kenya and Somalia (Figure 1). Samples analysed $(n=23)$ by QUB were provided by WFP via Merieux and included 11 of 15 suspect samples as well as 12 samples from retention stock in Turkey (Table 1).

Samples analysed by the FDA laboratory were obtained from a parallel investigation organized by the Ugandan government with the support of CDC. Seven suspect cereal samples were collected by the Ugandan Health Ministry from various local districts and three samples from retention stock were provided by WFP to be used as reference for analytical purpose.

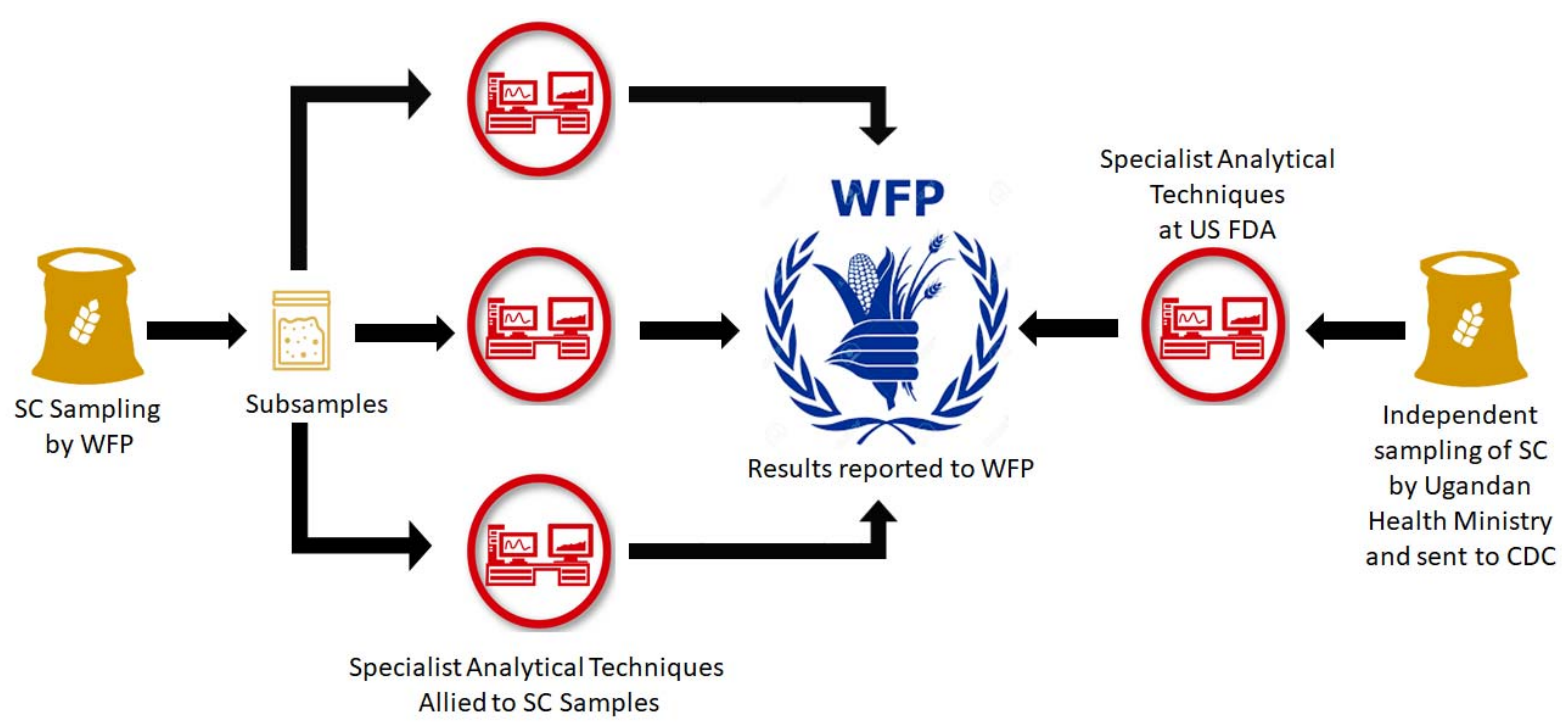

Figure 1: Collection and distribution of SC samples for analysis by expert laboratories

Table 1: SC samples sent to QUB and FDA from $1^{\text {st }}$ incident for laboratory analysis

\begin{tabular}{|c|c|c|c|}
\hline QUB Sample & Original Sample & $\underline{\text { Location Details }}$ & Lot \\
\hline$\underline{\text { Code }}$ & $\underline{\text { Code }}$ & & \\
\hline WFP-0001 & MOR-24 & SC Turkey returned from beneficiary & Unknown \\
\hline WFP-0002 & MOR-25 & SC Turkey returned from beneficiary & Unknown \\
\hline
\end{tabular}




\begin{tabular}{|c|c|c|c|}
\hline WFP-0003 & MOR-26 & SC Turkey returned from beneficiary & Unknown \\
\hline WFP-0004 & MOR-27 & SC Turkey returned from beneficiary & Unknown \\
\hline WFP-0005 & MOR-29 & SC Turkey returned from beneficiary & Unknown \\
\hline WFP-0006 & MOR-30 & SC Turkey returned from beneficiary & Unknown \\
\hline WFP-0007 & MOR-31 & SC Turkey returned from beneficiary & Unknown \\
\hline WFP-0008 & MOR-32 & SC Turkey returned from beneficiary & Unknown \\
\hline WFP-0009 & MOR-33 & SC Turkey returned from beneficiary & Unknown \\
\hline WFP-0010 & MOR-34 & SC Turkey returned from beneficiary & Unknown \\
\hline WFP-0011 & MOR-35 & SC Turkey returned from beneficiary & Unknown \\
\hline WFP-0012 & NG & Unknown lkea bag & Unknown \\
\hline WFP-0013 & $19-00005288$ & Dermirpolat, Turkey (SC reference sample) & 494.5 MT-2.Lot 2019EX001 \\
\hline WFP-0014 & $19-00005284$ & Dermirpolat, Turkey (SC reference sample) & 494.5 MT-2.Lot 2018EX032 \\
\hline WFP-0015 & $19-00005290$ & Dermirpolat, Turkey (SC reference sample) & 516 MT-4.Lot 2019EX001 \\
\hline WFP-0016 & $19-00005286$ & Dermirpolat, Turkey (SC reference sample) & 494.5 MT-3.Lot 2018EX032 \\
\hline WFP-0017 & $19-00005289$ & Dermirpolat, Turkey (SC reference sample) & 494.5 MT-3.Lot 2019EX001 \\
\hline WFP-0018 & $19-00005285$ & Dermirpolat, Turkey (SC reference sample) & 494.5 MT-2.Lot 2018EX032 \\
\hline WFP-0019 & $19-00005291$ & Dermirpolat, Turkey (SC reference sample) & 516 MT-3.Lot 2018EX026 \\
\hline WFP-0020 & $19-00005281$ & Dermirpolat, Turkey (SC reference sample) & 516 MT-3.Lot 2018EX026 \\
\hline WFP-0021 & $19-00005287$ & Dermirpolat, Turkey (SC reference sample) & 516 MT-4.Lot 2018EX032 \\
\hline WFP-0022 & $19-00005282$ & Dermirpolat, Turkey (SC reference sample) & 559 MT-10.Lot 2018EX031 \\
\hline WFP-0023 & $19-00005283$ & Dermirpolat, Turkey (SC reference sample) & $430 \mathrm{MT}-11 . \mathrm{Lot}$ 2018EX031 \\
\hline FDA-001 & Sample A & SC from Kangole Napak & Unknown \\
\hline FDA-002 & Sample B & SC from Lorengecora Napak & Unknown \\
\hline FDA-003 & Sample C & SC from Lokopo District & Unknown \\
\hline FDA-004 & Sample D & SC from Amudat District & Unknown \\
\hline FDA-005 & Sample E & SC from Amudat District & Unknown \\
\hline FDA-006 & Sample F & SC from the warehouse & Unknown \\
\hline FDA-007 & Sample G & SC from the warehouse & Unknown \\
\hline FDA-008 & $\begin{array}{c}\text { Sample } 5(19- \\
\text { 00005292) }\end{array}$ & $\begin{array}{l}\text { Dermirpolat, Turkey, (SC reference sample received } \\
\text { directly from WFP) }\end{array}$ & 494.5MT-3.Lot 2018EX032 \\
\hline FDA-009 & $\begin{array}{l}\text { Sample } 6(19- \\
\text { 00005293) }\end{array}$ & $\begin{array}{l}\text { Dermirpolat, Turkey, (SC reference sample received } \\
\text { directly from WFP) }\end{array}$ & 516MT-4.Lot 2018EX032 \\
\hline FDA-010 & $\begin{array}{l}\text { Sample } 7(19- \\
\text { 00005294) }\end{array}$ & $\begin{array}{c}\text { Dermirpolat, Turkey, (SC reference sample received } \\
\text { directly from WFP) }\end{array}$ & 494.5MT-2.Lot 2019EX001 \\
\hline
\end{tabular}




\subsection{Sample analysis}

Samples were analysed using a variety of instrumental techniques in the three expert laboratories. The techniques included LC-HRMS, GC-HRMS, GC-MS, LC-MSMS, FTIR and NIR.

\subsubsection{Sample preparation (QUB)}

Sample $(0.05 \mathrm{~g})$ was extracted in $1.5 \mathrm{~mL}$ of methanol/water solution $(1: 1, \mathrm{v} / \mathrm{v})$, mixed for 10 minutes, sonicated for 15 minutes at maximum frequency in a water bath at room temperature, centrifuged at 10,000 $\mathrm{g}$ for 10 minutes at $4^{\circ} \mathrm{C}$ and the supernatant collected $(1.0 \mathrm{~mL})$. Subsequently, the extract was filtered through a $0.22 \mu \mathrm{m}$ centrifuge tube filter $\left(10,000 \mathrm{~g}\right.$ at $4^{\circ} \mathrm{C}$ for 10 minutes). Filtered extracts were immediately transferred into maximum recovery vials for LC-HRMS analysis and a pooled sample acting as Quality Control (QC) was generated. Samples analyzed by the U.S. FDA were prepared in a generally similar fashion using water extraction and dilution with acetonitrile/1\% formic acid(Croley et al., 2020).

\subsection{Sample Preparation GC analysis (Merieux)}

Cereal samples were prepared following an acid/base organic extraction protocol prior to GC-MS analysis. Distilled water was added to cereal samples then extracted with a mix of organic solvent with the first extraction carried out under acidic conditions then the second extraction conducted under basic conditions. Two organic extracts were then combined and concentrated under a flux of nitrogen.(Christen, Bieri, \& Veuthey, 2007)

\subsection{Sample Preparation LC and GC-HRMS analysis (Merieux)}

Samples were extracted in acetonitrile/water solution, mixed for 10 minutes with a mechanical shaker, then water was removed by addition of anhydrous magnesium sulfate. Organic extract was transferred to vial and concentrated under reduce pressure before GC-HRMS analysis.

\subsection{LC-HRMS analysis (QUB)}

Analyses were carried out on an Agilent 1290 Infinity II LC system (Cheadle, UK) coupled to a 6545 QToF mass spectrometer (Santa Clara, CA, USA) equipped with a Dual Jet Stream electrospray ionisation source 
operating in positive or negative mode with a dual nebuliser for real time accurate mass correction. Instrument settings were as follow: gas temperature was set at $240^{\circ} \mathrm{C}$, drying gas flow at $10 \mathrm{~L} / \mathrm{min}$, nebulizer at $35 \mathrm{PSI}$, sheath gas temperature at $310^{\circ} \mathrm{C}$, and sheath gas flow at $11 \mathrm{~L} / \mathrm{min}$. The capillary voltage was set at $3.5 \mathrm{kV}$ in positive mode with a nozzle voltage of $300 \mathrm{~V}$ and $2.5 \mathrm{kV}$ in negative mode with a nozzle voltage of $700 \mathrm{~V}$, respectively. Fragmentor was set at $110 \mathrm{~V}$ with a skimmer at $65 \mathrm{~V}$. Mass spectra data were acquired in continuum mode using All lons methodology (low energy: $10 \mathrm{eV}$; medium energy: 20eV; high energy: $40 \mathrm{eV}$ ) over the range $\mathrm{m} / \mathrm{z} 50-1200$ with a scan time of $0.1 \mathrm{~s}$. A reference mass solution containing a purine base and hexakis $(1 \mathrm{H}, 1 \mathrm{H}, 3 \mathrm{H}$-tetrafluoropropoxy)phosphazine) (HP-921) in ACN/water containing $0.1 \%$ formic acid $(8: 2, v / v)$ was continuously infused into the MS via the dual nebulizer.

The chromatographic separation was conducted on an Agilent Zorbax Eclipse Plus C18 column (50 mm x $2.1 \mathrm{~mm}, 1.8 \mu \mathrm{m})$. The column oven temperature was set at $45^{\circ} \mathrm{C}$, injection volume at $5 \mu \mathrm{L}$ and flow rate at $0.6 \mathrm{~mL} / \mathrm{min}$. Mobile phase consisted of $(\mathrm{A})$ water with $0.1 \%$ formic acid and $(\mathrm{B})$ methanol with $0.1 \%$ formic acid. The gradient was set as follows: 0.50 min of $10 \%$ (B) followed by a linear increase from 10 to $99 \%$ (B) over $7 \mathrm{~min}$, isocratic cleaning step at $99 \%$ (B) for $1.5 \mathrm{~min}$, then returned to initial conditions $1 \%$ (B) over 0.1 min and column equilibration step at $10 \%$ (B) for 0.9 min.

Prior to all analyses $10 \mathrm{QCs}$ were injected in order to condition the system. For quality control pooled samples were injected at intervals of every 10 samples throughout the entire experiment to determine the chromatographic reproducibility of retention times and peak intensities.(Chatterjee, Chevallier, Wielogorska, Black, \& Elliott, 2019)

\subsection{LC-HRMS and MS/MS analysis (FDA)}

LC-HRMS and MS/MS analysis at US FDA were performed as described in reference ((Croley et al., 2020)). Briefly, analyses were carried out on a Shimadzu Nexera LC system (Shimadzu Corp, Kyoto, Japan) coupled to a Thermo Q-Exactive mass spectrometer (Thermofisher, San Antonio, CA,USA) equipped with a heated electrospray ionisation source operating in polarity switching mode. Mass spectra data were acquired in polarity switching mode at 70,000 resolving power for MS mode and separately in both positive and negative mode at 17,500 resolving power for MS/MS mode over the range $\mathrm{m} / \mathrm{z} 100-1200$. For data dependent acquisition, isolation window was set at $2 \mathrm{Da}$, with a collision energy set at $40 \mathrm{eV}$ and an intensity 
threshold of 8.3 E4 counts. The chromatographic separation was conducted on a Phenomenex Kinetex C18 column (150 mm x $2.1 \mathrm{~mm}, 100 \AA, 1.7 \mu \mathrm{m})$ at $0.4 \mathrm{~mL} / \mathrm{min}$. Mobile phase consisted of $(\mathrm{A})$ water with $0.1 \%$ formic acid and (B) methanol with $0.1 \%$ formic acid.

\subsection{GC-MS analysis (Merieux)}

Analyses were carried out on an Agilent 7890B GC coupled to an Agilent 5975C Single Quadripole mass spectrometer operating in Electron Impact ionisation mode with MS Source and MS Quad set up at $230^{\circ} \mathrm{C}$ and $150{ }^{\circ} \mathrm{C}$, respectively. MS instrument was tuned using PFTBA per manufacturer recommendations. Data were acquired in SIM-SCAN mode from 35-450 AMU. The chromatographic separation was performed on an Agilent HP-5MS UI (30 m $\times 250 \mu \mathrm{m} \times 0.25 \mu \mathrm{m})$ column using Helium carrier as a carrier gas at a constant flow of $1.0 \mathrm{~mL} / \mathrm{min}$. Gradient was as follow: initial temperature of $60^{\circ} \mathrm{C}$ was held for 5 minutes then ramped to $280^{\circ} \mathrm{C}$ at a rate of $5^{\circ} \mathrm{C} / \mathrm{min}$ and held for 30 minutes, followed by return to $60{ }^{\circ} \mathrm{C}$ at a rate of $15^{\circ} \mathrm{C} / \mathrm{min}$ and held for a further 5 minutes at initial temperature. Samples were injected in splitless mode set at $280 \circ \mathrm{C}$ using an Agilent straight liner with glass wool.

\subsection{LC-HRMS and GC-HRMS analysis (Merieux)}

GC analyses were carried out on a Thermo Scientific Q Exactive GC Orbitrap. Data were acquired in SIMSCAN mode from 35-450 AMU. The chromatographic separation was performed on a Thermo Scientific TG-5SILMS (30 m x $250 \mu \mathrm{m} \times 0.25 \mu \mathrm{m})$ column using Helium carrier as a carrier gas at a constant flow of $1.5 \mathrm{~mL} / \mathrm{min}$. Gradient was as follow: initial temperature of $50{ }^{\circ} \mathrm{C}$ was held for 5 minutes then ramped to 320 ${ }^{\circ} \mathrm{C}$ at a rate of $15{ }^{\circ} \mathrm{C} / \mathrm{min}$ and held for 20 minutes, followed by return to $50^{\circ} \mathrm{C}$. Data were analysed with TraceFinder 4.1 and Mass Frontier 7.0 (Thermo Fisher, US) and identification was based on NIST library. LC analyses were performed on Thermo Scientific Q Exactive LC Orbitrap using full scan mode from 701000 AMU. Chromatography was carried out using a Phenomenex Kinetex C18 column (3mm, $100 \mathrm{~mm}$, 2.6 $\mu \mathrm{m}$ ). Data were analysed using Mass Frontier 7.0, Compound Discoverer 2.1 (Thermo Fisher) and identification was based on library build with $\mathrm{m} / \mathrm{z}$ Cloud (Thermo Fisher) and Chemspider. 


\subsection{Spectroscopy Measurements}

Fourier-transform infrared spectroscopy (FT-IR) and Near-infrared spectroscopy (NIR) spectra were collected on the multi-module iS50 spectrometer (Thermofisher, Dublin, Ireland) at ambient temperature. The FT-IR samples were analysed on the benchtop FTIR with ATR accessory, diamond crystal and DLaTGS detector. Spectra were acquired in the $4000-400 \mathrm{~cm}^{-1}$ range with 32 scans and a resolution of 4 $\mathrm{cm}^{-1}$. The NIR samples $(5 \mathrm{~g})$ were poured onto the sample cup (diameter: $3.2 \mathrm{~cm}$, height: $1.5 \mathrm{~cm}$ ) spinner on the Integrating Sphere module of the instrument. Spectra were acquired in the $12000-4000 \mathrm{~cm}^{-1}$ range with 32 scans with a resolution of $8 \mathrm{~cm}^{-1}$. Three replicates of each sample were measured and averaged prior to data pre-processing.(Haughey, Galvin-King, Ho, Bell, \& Elliott, 2015)

\subsection{Proximate Analysis by NIR}

For benchtop NIR analysis, the spectra were recorded on an Antaris II FT-NIR (Thermo Fisher Scientific, Dublin, Ireland). The samples $(10 \mathrm{~g})$ were poured onto the sample cup spinner on the Integrating Sphere module of the instrument. All the spectra were computed at $8 \mathrm{~cm}^{-1}$ resolution across the spectral range $12,000-3800 \mathrm{~cm}^{-1}$ and ran in triplicate. Instrument control and initial spectral manipulation were performed with Result Integration software (Thermo Fisher Scientific, Dublin, Ireland). The spectra were recorded at ambient temperature and a total of 64 scans were acquired for each spectrum. For the proximate analysis comparison, off the shelf INGOT calibrations were used (Aunir, Towcester, UK) and were corrected for bias using reference materials supplied by Aunir (Haughey, Galvin-King, Malechaux, \& Elliott, 2015).

\subsection{Data analysis and Results (QUB)}

Raw data generated by the instrument were processed using Mass Hunter suite (Agilent Technologies, Santa Clara, CA, USA) including Qual 10.0 and Personal Compound Database and Library Manager 8.1 (PCDL). For this analysis, a theoretical database including mycotoxins, plant alkaloids and other common contaminants was generated based on theoretical mass and known fragment from the literature (Figure 2). Identification was performed by comparison of the ion profile of the fragmentation for the substances experimental detected with the profile included in the database. 

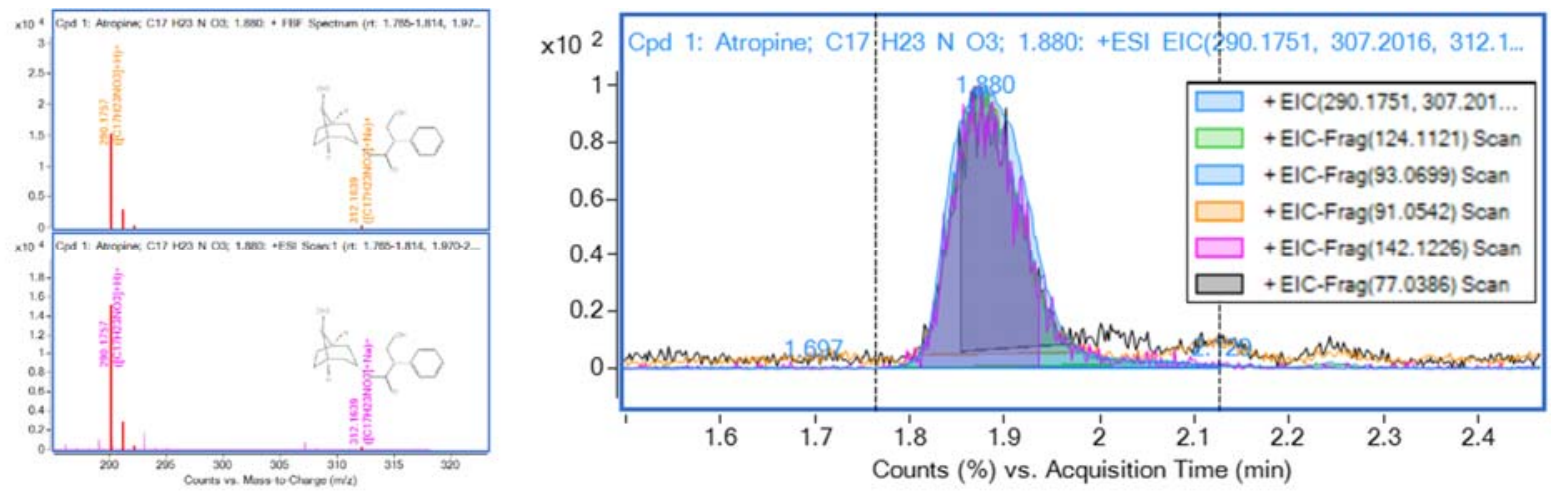

Figure 2: Match based on mass accuracy for atropine parent ion and sodium adduct (left).

Complementary match based on fragment (right)

\subsection{Chemometrics analysis at QUB}

Chemometric analysis was carried out using the software SIMCA 15 (Umetrics, Sweden). Prior to model development pre-processing was conducted. The spectral region, $2800-1800 \mathrm{~cm}^{-1}$, in the FT-IR spectra and the region, $12000-9000 \mathrm{~cm}^{-1}$, in the NIR spectra contain no relevant sample information and were therefore removed before data analysis. The spectral data was then processed using common scaling and pre-processing methods, and combinations thereof. The pre-processing methods used were derivatives, Savitzky-Golay (SG) and Standard normal variate (SNV). Principal Component Analysis (PCA), an unsupervised technique was used to explore differences between samples based purely on spectral differences (Black, Haughey, Chevallier, Galvin-King, \& Elliott, 2016).

\section{Results and discussion}

3.1 Review of the analytical work conducted on the Super Cereals for the $1^{\text {st }}$ incident.

This section focuses on the analytical work performed on Super Cereals involved in the incident by Queen's University Belfast (QUB), Merieux Nutrisciences and Food and Drug administration (FDA) on behalf of $\mathrm{CDC}$, and a conclusion on the root causes of the intoxications. 
The three laboratories involved in mass spectrometry (MS) measurement carried out the analysis in an independent manner and results were then compared. Heavy metal analysis was carried out by the FDA on their sample set using ICP-MS for level of Chromium, Arsenic, Cadmium, Mercury and Lead. All results were within their maximum permitted levels thus removing the likely cause of contamination due to heavy metals (Croley et al., 2020).

In order to investigate possible small molecule polar organic contamination, untargeted screening methodologies using hyphenated mass spectrometry in conjunction with database interrogation becoming more available and easier to deploy. The overall approach followed by all laboratories to analyse these cereal samples was quite similar. Following an untargeted sample preparation, extracts were injected into GC or LC-MS using full scan mode in conjunction with a ballistic chromatographic gradient. Raw data were then processed and screened against commercial or in-house contaminant/toxin databases in order to identify possible suspect compounds and deliver a qualitative result (Christen et al., 2007).

All laboratories used LC-HRMS (LC-Orbitrap for FDA and Merieux, LC-QTof for QUB) and were able to identify the suspect analytes atropine and scopolamine with matching exact mass (less than 1ppm difference), isotopic pattern and fragmentation patterns. Identifications provided by such means of untargeted screening can only be confirmed after target analyses with certified reference materials. Pure analytical standards of suspect analytes were available at the FDA and Merieux and were used to confirm the identities of the toxins involved and further quantitation using a targeted methodology. Furthermore, Merieux and FDA laboratories carried out analysis with GC-MS and were able to confirm the identity of contaminants present in some of the cereal samples tested (Croley et al., 2020).

Quantification for the sample set obtained by FDA was carried out using LC-MS/MS analysis for which a limit of quantification for atropine and scopolamine were $3.0 \mu \mathrm{g} / \mathrm{kg}$ and $1.5 \mu \mathrm{g} / \mathrm{kg}$, respectively. From this unique sample set, 3 samples collected by the Ugandan Health Ministry from a local district contained high level of atropine and scopolamine while retention samples as well as some local samples only contained trace or low level of toxins (Table 2).

In the absence of tropane alkaloid (TA) standards, QUB was only able to provide a qualitative result (Table 2) based on a theoretical database. Quantitative analysis provided by Merieux on the common samples 
analysed by the laboratories confirmed high level of tropane alkaloids for 4 samples (WFP-0002, 0004, 0009, 0012) identified by QUB as TA contaminated. All remaining samples were also shown to be contaminated with atropine and scopolamine at relatively low-level ranging from $2.1 \mu \mathrm{g} / \mathrm{kg}$ to $152 \mu \mathrm{g} / \mathrm{kg}$ and $1 \mu \mathrm{g} / \mathrm{kg}$ to $17.9 \mu \mathrm{g} / \mathrm{kg}$, respectively and these concentrations were not detected using LC-HRMS methodology employed by QUB. Indeed, despite recent progress in high resolution instruments, specific instrumentation for targeted analysis such as triple quadrupole or trap mass spectrometer are still considered 10 to 100 time more sensitive and are recognized as "gold standard" for quantitative analysis(Jakabova, Vincze, Farkas, Kilar, Boros, \& Felinger, 2012). However, the analysis undertaken at QUB was able to detect the harmful levels (Perharič, Juvan, \& Stanovnik, 2013) of contamination of the TAs.

Table 2: Mass spectrometry results obtained using qualitative methodology at QUB and quantitative methodology at Merieux (results in parentheses). FDA data is from reference (Croley et al., 2020)

\begin{tabular}{|c|c|c|}
\hline QUB Sample Code & Atropine & Scopolamine \\
\hline WFP-0001 & Not detected $(2.1 \mu \mathrm{g} / \mathrm{kg})$ & Not detected $(1 \mu \mathrm{g} / \mathrm{kg})$ \\
\hline WFP-0002 & Detected $(2100 \mu \mathrm{g} / \mathrm{kg})$ & Detected $(300 \mu \mathrm{g} / \mathrm{kg})$ \\
\hline WFP-0003 & Not detected $(20.8 \mu \mathrm{g} / \mathrm{kg})$ & Not detected $(3 \mu \mathrm{g} / \mathrm{kg})$ \\
\hline WFP-0004 & Detected $(1800 \mu \mathrm{g} / \mathrm{kg})$ & Detected $(250 \mu \mathrm{g} / \mathrm{kg})$ \\
\hline WFP-0005 & Not detected $(83 \mu \mathrm{g} / \mathrm{kg})$ & Not detected $(10.6 \mu \mathrm{g} / \mathrm{kg})$ \\
\hline WFP-0006 & Not detected $(87 \mu \mathrm{g} / \mathrm{kg})$ & Not detected $(10.3 \mu \mathrm{g} / \mathrm{kg})$ \\
\hline WFP-0007 & Not detected $(152 \mu \mathrm{g} / \mathrm{kg})$ & Not detected $(17.9 \mu \mathrm{g} / \mathrm{kg})$ \\
\hline WFP-0008 & Not detected $(80 \mu \mathrm{g} / \mathrm{kg})$ & Not detected $(11.6 \mu \mathrm{g} / \mathrm{kg})$ \\
\hline WFP-0009 & Detected $(8500 \mu \mathrm{g} / \mathrm{kg})$ & Detected $(1000 \mu \mathrm{g} / \mathrm{kg})$ \\
\hline WFP-0010 & Not detected $(99 \mu \mathrm{g} / \mathrm{kg})$ & Not detected $(12.1 \mu \mathrm{g} / \mathrm{kg})$ \\
\hline WFP-0011 & Not detected $(18 \mu \mathrm{g} / \mathrm{kg})$ & Not detected $(3.6 \mu \mathrm{g} / \mathrm{kg})$ \\
\hline WFP-0012 & Detected $(17200 \mu \mathrm{g} / \mathrm{kg})$ & Detected $(2400 \mu \mathrm{g} / \mathrm{kg})$ \\
\hline WFP-0013 & Not detected & Not detected \\
\hline WFP-0014 & Not detected & Not detected \\
\hline WFP-0015 & Not detected & Not detected \\
\hline WFP-0016 & Not detected & Not detected \\
\hline WFP-0017 & Not detected & Not detected \\
\hline WFP-0018 & Not detected & Not detected \\
\hline
\end{tabular}




\begin{tabular}{|c|c|c|}
\hline WFP-0019 & Not detected & Not detected \\
\hline WFP-0020 & Not detected & Not detected \\
\hline WFP-0021 & Not detected & Not detected \\
\hline WFP-0022 & Not detected & Not detected \\
\hline WFP-0023 & Not detected & $112 \mu \mathrm{g} / \mathrm{kg}$ \\
\hline FDA-001 & $883 \mu \mathrm{g} / \mathrm{kg}$ & $3621 \mu \mathrm{g} / \mathrm{kg}$ \\
\hline FDA-002 & $28633 \mu \mathrm{g} / \mathrm{kg}$ & $7457 \mu \mathrm{g} / \mathrm{kg}$ \\
\hline FDA-003 & $54574 \mu \mathrm{g} / \mathrm{kg}$ & Not detected \\
\hline FDA-004 & Not detected & $2803 \mu \mathrm{g} / \mathrm{kg}$ \\
\hline FDA-005 & $26818 \mu \mathrm{g} / \mathrm{kg}$ & $17 \mu \mathrm{g} / \mathrm{kg}$ \\
\hline FDA-006 & $41 \mu \mathrm{g} / \mathrm{kg}$ & Trace \\
\hline FDA-007 & $20 \mu \mathrm{\mu g} / \mathrm{kg}$ & Trace \\
\hline FDA-008 & Trace & Trace \\
\hline FDA-009 & $44 \mu \mathrm{g} / \mathrm{kg}$ & Trace \\
\hline FDA-010 & $12 \mu \mathrm{g} / \mathrm{kg}$ & \\
\hline
\end{tabular}

\subsection{Review of the analytical work conducted on the Super Cereals from the third incident.}

The third incident occurred in Uganda during August 2019 and initial reports indicated that people were presenting with symptoms very similar to those in the previous incidences again implicating contaminated $\mathrm{SC}$ as the cause of the illness. This raised the question of the supply chains and whether contaminated material was available from another source, as the supplier implicated was a Belgian company. Further investigation was instigated by WFP and a series of samples were shipped to QUB for analysis. These were assigned sample id WFP-0024 to WFP-0039 (see Table 3) and included retention samples (WFP0024 to WFP -0031), suspect samples and store samples (WFP-0036 to WFP-WFP-0038). Initial analysis of this sample set was carried out using similar screening methodology by LC-HRMS as previously used for the $1^{\text {st }}$ incident. Known contaminated samples from the $1^{\text {st }}$ incident (WFP-0002, 0004, 0009, 0012) were used as positive controls for atropine and scopolamine in the absence of pure reference standard. Samples WFP-0032, 0033, 0034 were found contaminated with high level of tropine alkaloid comparable to the previous incident. 
Table 3: Samples sent to QUB from the third incident in August 2019 with tropane alkaloid detected by LCHRMS

\begin{tabular}{|c|c|c|c|c|}
\hline $\begin{array}{c}\text { QUB Sample } \\
\text { Code }\end{array}$ & Original Sample Code & From & Atropine & Scopolamine \\
\hline WFP-0024 & 47401 & Zulte, Belgium & Not detected & Not detected \\
\hline WFP-0025 & 47493 & Zulte, Belgium & Not detected & Not detected \\
\hline WFP-0026 & 47268 & Zulte, Belgium & Not detected & Not detected \\
\hline WFP-0027 & 47982 & Zulte, Belgium & Not detected & Not detected \\
\hline WFP-0028 & 47607 & Zulte, Belgium & Not detected & Not detected \\
\hline WFP-0029 & 47564 & Zulte, Belgium & Not detected & Not detected \\
\hline WFP-0030 & 47955 & Zulte, Belgium & Not detected & Not detected \\
\hline WFP-0031 & 47107 & Zulte, Belgium & Not detected & Not detected \\
\hline WFP-0032 & Sample 1 & $\begin{array}{l}\text { SC returned from beneficiary Saburuni } \\
\text { Jackline }\end{array}$ & Detected & Detected \\
\hline WFP-0033 & Sample 2 & SC returned from beneficiary Akwero Suzan & Detected & Detected \\
\hline WFP-0034 & Sample 3 & SC returned from beneficiary Aber Sunday & Detected & Detected \\
\hline WFP-0035 & Sample 4 & SC returned from beneficiary Adyee Regina & Not detected & Not detected \\
\hline WFP-0036 & Sample 7 & SC & Not detected & Not detected \\
\hline WFP-0037 & Sample 8 & SC & Not detected & Not detected \\
\hline WFP-0038 & Sample 9 & SC & Not detected & Not detected \\
\hline WFP-0039 & Sample 11 & SC returned from beneficiary Galla Mary & Not detected & Not detected \\
\hline
\end{tabular}

Following the analysis of the samples by mass spectrometry, further investigations using FTIR, NIRS and chemometrics were instigated to determine if samples from the third incident were related in any way to the previous incidents. By using non-targeted analyses in this way, which affords a detailed profile of the representative sample, it is possible to compare the profile of the sample in question to profiles gathered previously that represent historic material that has been shown to be fit for purpose. Appropriate chemometrics can then be used to discern if there are differences between the sample in question and historic samples.

PCA chemometric analysis was carried out on SC samples sent by WFP from the $1^{\text {st }}$ and $3^{\text {rd }}$ incidents. Figure 3 shows the PCA plots for the NIR and FTIR data for control/retained samples from the two suppliers, Turkey ( $1^{\text {st }}$ incident) and Belgium ( $3^{\text {rd }}$ incident). The resulting plots indicate that the PCA models show 
A: NIR Data

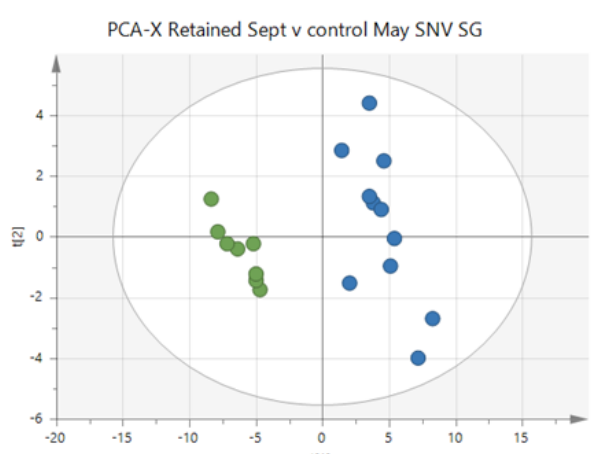

$R 2 \times[1]=0.847, R 2 \times[2]=0.105$, Ell11ipse: Hotelling's T2 (958)
B: FTIR Data

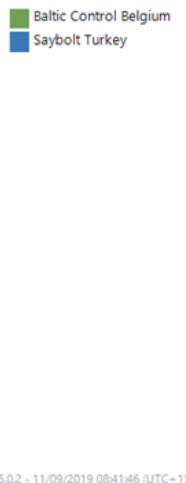

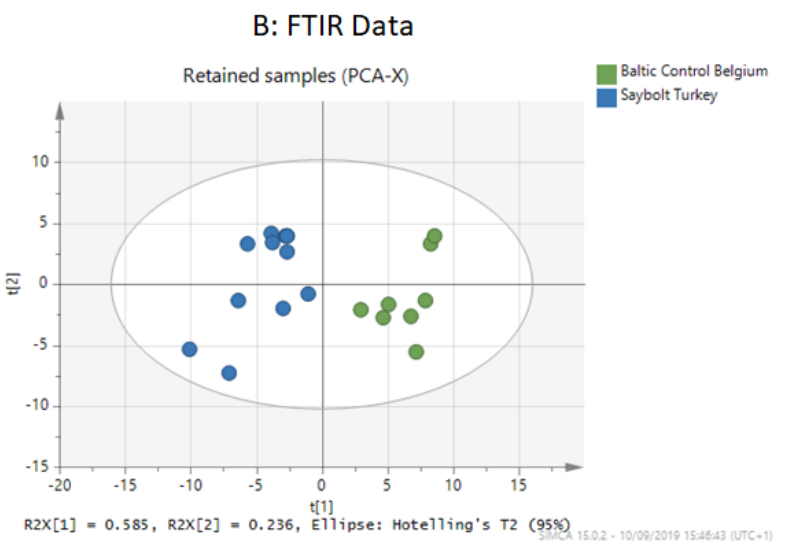

Figure 3: PCA plots of (A) NIR and (B) FTIR data from control/retained samples from the two companies (Turkey and Belgium) implicated in the incidents.

A: NIR Data

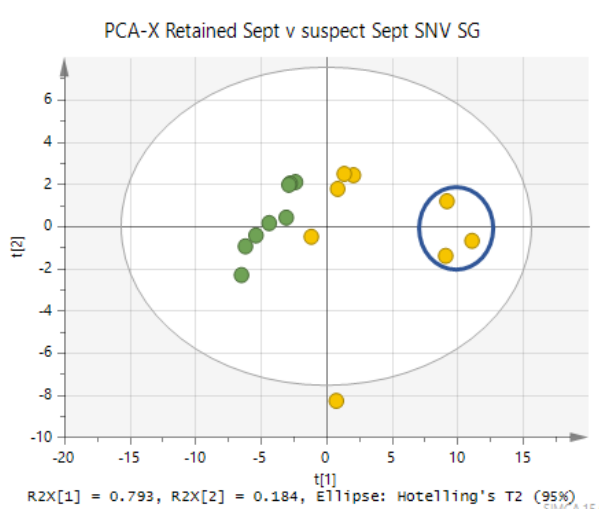

B: FTIR Data

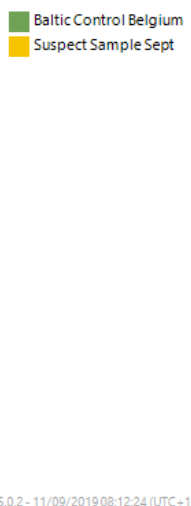

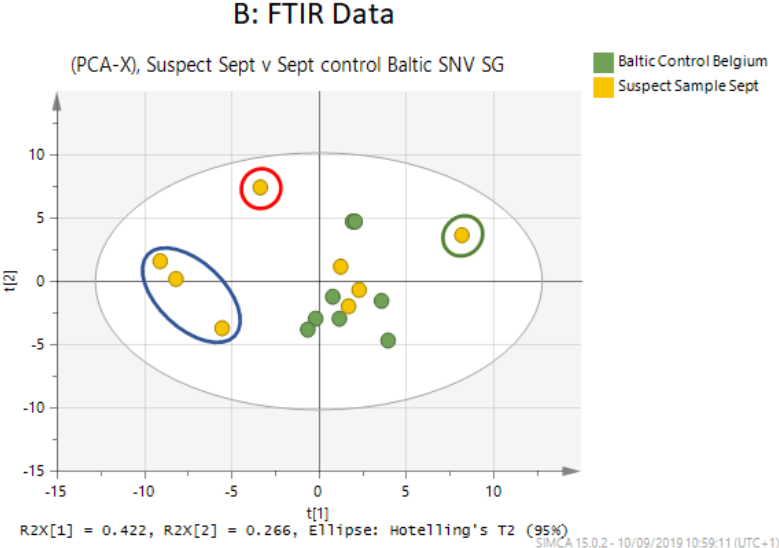

Figure 4: PCA plots for (A) NIR and (B) FTIR data for retained samples (Belgian supplier) and the $3^{\text {rd }}$ incident suspect samples.

The next investigation was to observe if there were any differences between the retained samples from the Belgian supplier and the suspect samples recovered from the $3^{\text {rd }}$ incident. Figure 4 shows the PCA plots 
for the NIR and FTIR data for retained samples (WFP-0024 to WFP-0031, Belgium) and the $3^{\text {rd }}$ incident samples identified as being suspect (WFP-0032 to WFP-0039). It was noticeable in both plots that the samples (WFP-0032 to WFP-0034), circled blue, were obtained from households where sickness had been reported and appear as distinct clusters, separated from the main Belgian SC samples. The SC store samples (WFP-0036 to WFP-0038) were found to be separated from the suspect samples (WFP-0032, WFP-0033,WFP-0034 \& WFP-0039) and closer to the retained samples from the Belgian supplier i.e. distinct clusters were observed in the PCA plots, indicating that the suspect samples were different in profile to those obtained from the Belgian supplier. In the FTIR PCA plot, the sample circled green (WFP0035) was found to be remote from the main Belgium control/retained samples and was from a household where there was no sickness reported. The sample falling outside the ellipse in the NIR PCA plot and the sample circled red in the FTIR plot was the same sample (WFP-0039) which had been found to have caused intoxication in the household it had been retrieved from. This sample appears to have a very different profile to the other samples analysed which may be explained by the observations which are made in the proximate analysis section.
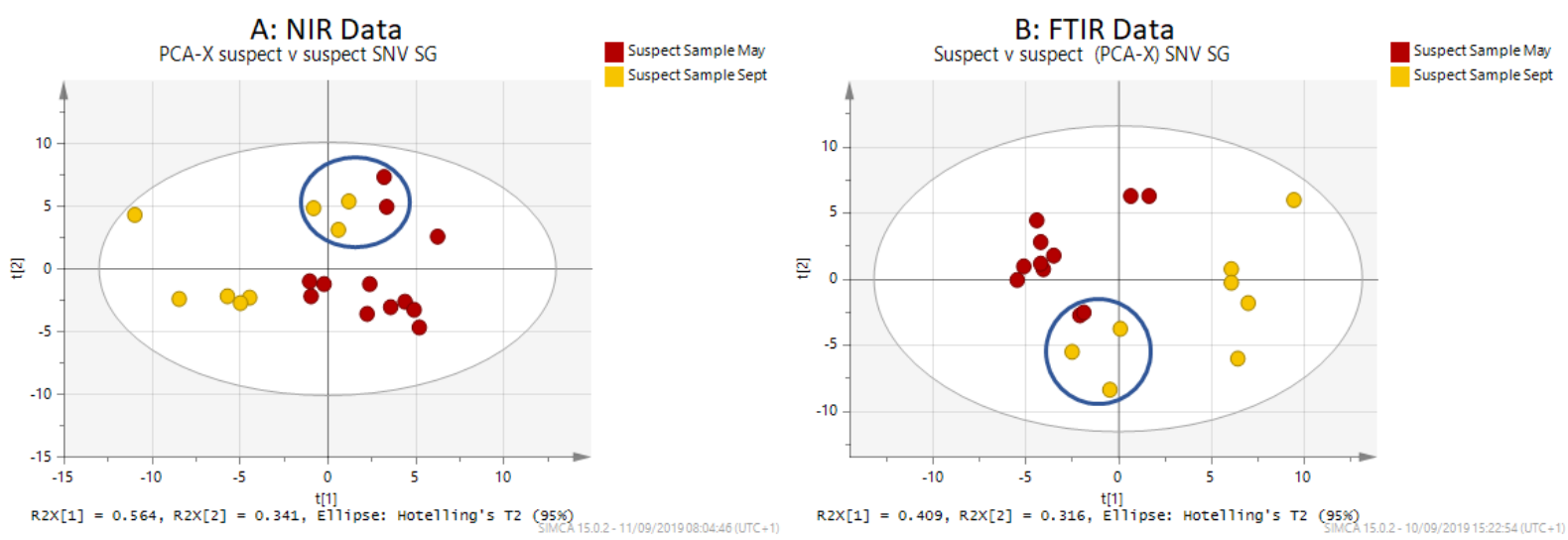

Figure 5 PCA plots for (A) NIR and (B) FTIR data for the suspect samples taken in $1^{\text {st }}$ and $3^{\text {rd }}$ incidents.

Therefore, based on the data in Figure 4, the suspect samples and control samples from the $3^{\text {rd }}$ incident appeared to be different. It was decided to make a further comparison between the suspect samples taken in the $1^{\text {st }}$ and $3^{\text {rd }}$ incidents. Figure 5 shows the NIR and FTIR PCA plots for the suspect samples taken in $1^{\text {st }}$ incident (WFP-0001 to WFP-0012) and those taken in the $3^{\text {rd }}$ incident (WFP-0032 to WFP-0039). The 
samples with the blue circle in both plots were found to be from households with reported sickness in both incidents with the yellow dots represented samples (WFP-0032 to WFP-0034) from the $3^{\text {rd }}$ incident obtained from households with sickness whilst the red dots represented the "mid-wife" sample (WFP-0012) (1 ${ }^{\text {st }}$ incident) which was the known to have caused illness, whilst the other red dot represented a suspect sample (WFP-0004, $1^{\text {st }}$ incident) which had been obtained and consequently found to have a high levels of atropine and scopolamine (see Table 2). As these suspect samples clustered closely together from both incidents and are indistinguishable based on both FTIR and NIR spectral data, it strongly indicated a cross-over between different batches/bags implicated in the $1^{\text {st }}$ and $3^{\text {rd }}$ incidents.

In summary, the PCA plots of the data indicated a link between the incidents for which suspect samples were taken in the $1^{\text {st }}$ and $3^{\text {rd }}$ incidents and also that the SC samples from the two different suppliers could be distinguished using NIR and FTIR and chemometrics. Samples (WFP-0032 to WFP-0034) from the batch which had reported intoxication in the $3^{\text {rd }}$ incident continuously demonstrated strong similarities with the two suspect samples from $1^{\text {st }}$ incident (one labelled "mid-wife" (WFP-0012, from a household with sickness) and WFP-0004 which was found to have significant levels of atropine and scopolamine). Sample WFP-0039, obtained from a household during the $3^{\text {rd }}$ incident is continually falling near or outside the ellipse of the PCA plots, indicating significant disparity between it and all the other samples which indicated that this particular sample was different to the others. Samples WFP-0032, WFP-0033, WFP-0034 and WFP0039, which came from households with reported intoxication ( $3^{\text {rd }}$ incident) were shown to be different from the retained samples (Belgian samples) and samples obtained from SC stores (Samples WFP-0036 to WPF-0038 ), which indicated that these samples did not come from the same producer.

Based on the metadata (Table 3) associated with the $3^{\text {rd }}$ incident, the samples obtained from SC stores have the same producer (Belgian) as the retained samples, whereas those obtained from households with suspect samples (WFP-0032,WFP-0033,WFP-0034 and WFP-0039) had unidentified producers based on the supplied meta-data.

\section{Proximate Analysis Results}


The SC foodstuff has maximum and minimum specifications for certain analytical parameters including moisture $(<10 \%)$ and protein $(>14 \%)$ (Table 4). A range of Ingot Calibrations from AUNIR (UK) which are based on NIRS data and were developed to give proximate analysis of animal feed and ingredients were used as calibrants. It was decided to use one of these calibrations (Group 60: Low Protein Low Oil) to give a baseline reading on parameters associated with the SC foodstuff. For moisture analysis (Figure $6(A)$ ) the Belgian retained samples and store samples (WFP-0036 to WPF-0038) as well as the Turkish retained samples ( 1 st incident, WFP-0013 to WFP-0023) have moisture levels at $<10 \%$ which is within specification. It is noteworthy to point out that suspect samples ( $3^{\text {rd }}$ incident, WFP-0032 to WFP-0034 \& WFP-0039) and the "midwife" sample (1st incident, WFP-0012) have moisture levels $>10 \%$ which were outside of the specification parameter. The fact that suspect samples appear to contain more moisture and coupled with the fact it was found that they contained Datura seeds (PCR test, results not shown), might be an explanation why these samples had a darker appearance. Acid Detergent Fiber (ADF) was another parameter applied to show potential differences between retained samples and suspect samples from both incidents. ADF is a measure of the percentage of the plant material that is difficult to digest, and this includes cellulose, lignin, and silica. The retained samples from both incidents (Belgium and Turkey) have lower levels of ADF (Figure $6(B)$ ) than the suspect samples which may be due to the latter having Datura seeds present. These suspect samples had been tested using Next Generation Sequencing (NGS) Metabarcoding Analysis carried out at Merieux indicating the presence of Datura species (results not shown). Datura species contain high concentrations of scopolamine and atropine, among other tropane alkaloids, in both the plant body and seeds, with the highest concentrations found within the seeds. With regards to the protein levels (Figure $6(C)$ ), the Belgian Samples ( $3^{\text {rd }}$ incident) have indicative levels of protein that were within specification i.e. $>14 \%$. However, all Turkish retained samples and all suspect samples had protein levels below the specification level $(<14 \%)$. Sample WFP-0039 was found to have parameters that were out of specification with moisture levels at $\sim 11 \%$, protein at $\sim 13.5 \%$ and ADF at $\sim 4.7 \%$ which may explain why this particular sample appeared as an outlier in the previous PCA chemometric model analysis (Figure 4). 
Table 4: Specifications for SC from WFP including moisture, protein, fat, fibre and ash.

405

406

407

408

409
A

Group 60 Moisture: Belgian \& Turkish SC

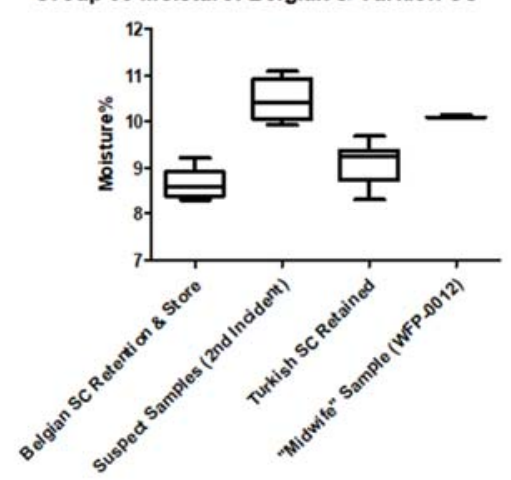

B

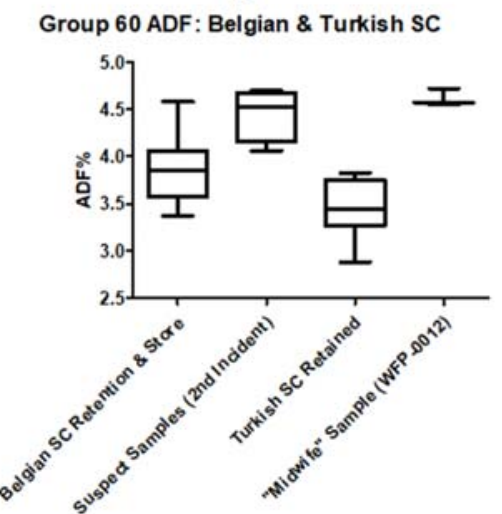

C

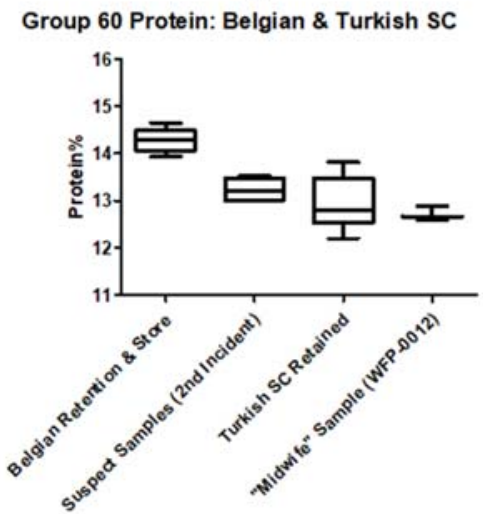

Figure 6 Proximate analysis content (A) Moisture; (B) ADF; (C) Protein

\section{Conclusions}

Food poisoning events linked with food aid are extremely rare and the rigor of the investigations undertaken to identify the cause showed the seriousness with which WFP viewed the incidents. While SC was suspected early in the investigations, this had to be confirmed and the root causes of the illnesses identified. Independent analysis by 3 laboratories using high resolution mass spectrometry indicated the cause was tropane alkaloids (TA) contaminated SC. The third incident which occurred a few months later, implicating a different supply chain, was extremely worrying to the WFP. However, the investigation of this by QUB using a range of spectroscopic tools was of huge importance in that the linkage between all three incidents and the initial Turkish supply chain was established. According to WFP, it appears highly likely that some of the contaminated material that was withdrawn from distribution was stolen from a warehouse 
and transported to another region of the country. Further to these investigations and to compliment the data collected, the WHO launched a call in late 2019 for further information and scientific advice on the occurrence of tropane alkaloids, risk assessments and evaluations related to SC, supplements, grains and pulses (Lipp \& Petersen, 2019). This advice will help the WFP set operational limits related to its food specifications.

\section{Acknowledgments}

The authors wish to thank US FDA Center for Food Safety and Applied Nutrition for sharing their results and methodologies.

\section{Author Contributions}

C.T. Elliott managed the project, collected and analysed metadata and drafted the manuscript. S.A. Haughey analysed spectroscopy data and drafted the manuscript. C. McVey acquired spectroscopy data. O.P. Chevallier acquired and analysed mass spectrometry data and drafted the manuscript. 
Abia, W., Nugent, A. P., Montgomery, H., \& Elliott, C. T. (2020). Tropane alkaloid contamination of agricultural commodities and cereal-based food products in relation to consumer health: Learnings from the 2019 Uganda food aid outbreak. Trends in Food Science and Technology, Unpulished results.

Black, C., Haughey, S. A., Chevallier, O. P., Galvin-King, P., \& Elliott, C. T. (2016). A comprehensive strategy to detect the fraudulent adulteration of herbs: The oregano approach. Food Chemistry, 210, 551-557. https://doi.org/10.1016/j.foodchem.2016.05.004.

Chatterjee, N. S., Chevallier, O. P., Wielogorska, E., Black, C., \& Elliott, C. T. (2019). Simultaneous authentication of species identity and geographical origin of shrimps: Untargeted metabolomics to recurrent biomarker ions. Journal of Chromatography A, 1599, 75-84. https://doi.org/10.1016/j.chroma.2019.04.001.

Christen, P., Bieri, S., \& Veuthey, J.-L. (2007). Analysis of Tropane Alkaloids in Biological Matrices. In Modern Alkaloids (pp. 339-367).

Croley, T., Knolhoff, A., O’ Donnell, C., Mangrum, B., Fong Sam, J., Callahan, J., \& Henderson, C. (2020). Food poisoning outbreak caused by consumption of relief food contaminated by jimsonweed (Datura stramonium): Napak and Amudat Districts, Uganda, March 2019. Personal communication.

Flynn, D., \& Beach, C. (2019). FDA and CDC helping with Ugandan outbreak investigation. Food Safety News Retrieved from: https://www.foodsafetynews.com/2019/06/fda-and-cdc-helping-with-ugandan-outbreakinvestigation/ Accessed.

Haughey, S. A., Galvin-King, P., Ho, Y. C., Bell, S. E. J., \& Elliott, C. T. (2015). The feasibility of using near infrared and Raman spectroscopic techniques to detect fraudulent adulteration of chili powders with Sudan dye. Food Control, 48, 75-83. https://doi.org/10.1016/j.foodcont.2014.03.047.

Haughey, S. A., Galvin-King, P., Malechaux, A., \& Elliott, C. T. (2015). The use of handheld near-infrared reflectance spectroscopy (NIRS) for the proximate analysis of poultry feed and to detect melamine adulteration of soya bean meal. Analytical Methods, 7(1), 181-186. https://doi.org/10.1039/c4ay02470b.

Jakabova, S., Vincze, L., Farkas, A., Kilar, F., Boros, B., \& Felinger, A. (2012). Determination of tropane alkaloids atropine and scopolamine by liquid chromatography-mass spectrometry in plant organs of Datura species. Journal of Chromatography A, 1232, 295-301. https://doi.org/10.1016/j.chroma.2012.02.036.

Lipp, M., \& Petersen, K. (2019). Call for Data on Hyoscyamine, Hyoscyamine and Scopolamine. Retrieved from: https://www.who.int/news-room/articles-detail/hyoscyamine-hyoscyamine-and-scopolamine-(deadline-31january-2020) Accessed 04/08/2020.

Perharič, L., Juvan, K. A., \& Stanovnik, L. (2013). Acute effects of a low-dose atropine/scopolamine mixture as a food contaminant in human volunteers. J Appl Toxicol, 33(9), 980-990. https://doi.org/10.1002/jat.2797.

Whitworth, J. (2019). Tropane alkaloids caused Ugandan food aid outbreaks. Food Safety News Retrieved from: https://www.foodsafetynews.com/2019/11/tropane-alkaloids-caused-ugandan-food-aid-outbreaks/ Accessed 04/08/2020. 